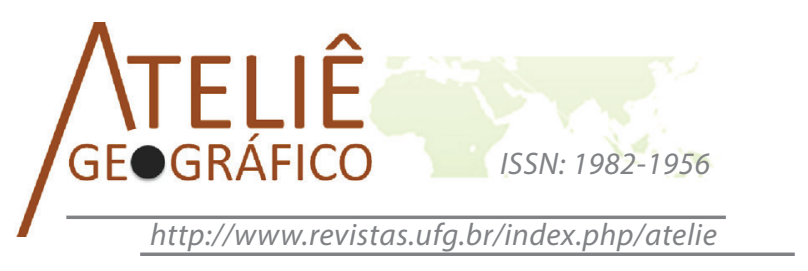

\title{
A Cartografia Escolar no processo de ensino- -aprendizagem: o Hipermapa e sua utilização na Educação Ambiental em Quevedos/RS
}

\author{
The School Cartography in the teaching-learning process: \\ The Hypermap and its use in Environmental Education in \\ Quevedos/RS
}

\section{La Cartografia de la Escuela en el proceso de enseñanza- -aprendizaje: el Hipermapa y su uso en la Educación Ambiental en Quevedos/RS}

\author{
Natália Lampert Batista \\ Universidade Federal de Santa Maria \\ natilbatista3@gmail.com \\ Roberto Cassol \\ Universidade Federal de Santa Maria \\ rtocassol@gmail.com \\ Elsbeth Léia Spode Becker \\ Centro Universitário Franciscano \\ Elsbeth.geo@gmail.com
}

\begin{abstract}
Resumo
A Geografia possui como objeto de análise a relação sociedade-natureza e, neste contexto, a temática ambiental é fortemente marcada no seu discurso. Os mapas revelam, então, uma complexa e valiosa linguagem para a compreensão do espaço geográfico. Nesse sentido, o presente estudo teve como objetivo geral contribuir para estudos geográficos de Cartografia Escolar enfatizando problemas ambientais de Quevedos/RS. O método científico utilizado foi o fenomenológico e a forma de abordagem foi qualitativa e descritiva. Com base nos resultados da pesquisa, acredita-se que as práticas vinculadas ao entendimento ambiental local, como a construção de mapas mentais, a utilização de materiais de ensino voltados ao município (Hipermapa) e a reflexão sistematizada e escrita sobre a sua realidade ambiental contribuem para o entendimento do espaço e das verdades temporárias sobre o "mundo" de modo articulado, inter-relacional e sistêmico, permitindo um
\end{abstract}


pensar mais reflexivo e despertando o sentimento de pertencimento e de identidade dos educandos.

Palavras-chave: Estudo do lugar. Espaço vivido. Pertencimento.

\begin{abstract}
Geography studies the relationship between society and nature, and as a consequence environmental issues have been reinforced by its findings. Therefore, maps are seen as a complex and valuable means for the understanding of geographical areas. This study aimed to contribute to the geographical research regarding School Cartography by drawing attention to environmental problems in the municipality of Quevedos/ RS. It consisted of a phenomenological research study which combined qualitative and quantitative approaches. Based on the results, it is believed that the practices linked to the local environmental understanding, such as the construction of mental maps, the use of teaching materials related to the municipality (Hypermap), and the written systematic thinking about its environmental reality contribute to the understanding of geographical space and temporary truths about the 'world' in a pivotal, interrelated and systemic way. This allows the students to think more thoughtfully, thus developing a sense of belonging and identity.
\end{abstract}

Keywords: The study of the area. Living space. Belonging

\begin{abstract}
Resumen
Geografía tiene como objeto de análisis de la relación entre la sociedad y la naturaleza, y en este contexto, la cuestión ambiental está fuertemente marcada en su discurso. Los mapas revelan, pues, un lenguaje complejo y valioso para la comprensión del espacio geográfico. En este sentido, el presente estudio tuvo como objetivo contribuir a los estudios geográficos de Cartografía de la Escuela enfatizando problemas ambientales en Quevedos/RS. El método científico utilizado fue fenomenológico y la forma de abordar fue cualitativa y descriptiva. Con base en los resultados, se cree que las prácticas vinculadas a la comprensión del medio ambiente local, ya que la construcción de mapas mentales, el uso de materiales didácticos dirigidos a la municipalidad (Hipermapa) y la reflexión sistemática y escribir sobre su realidad ambiental contribuyen para la comprensión del espacio y verdades temporales sobre el "mundo" de una manera articulada, inter-relacional y sistémica, lo que permite un pensar más reflexivo y despertar el sentimiento de pertenencia y la identidad de los estudiantes.
\end{abstract}

Palabras clave: Lugar de estudio. Espacio vivido. La pertenencia.

\title{
Considerações Iniciais
}

A reflexão sobre a situação do planeta e da humanidade pode soar uma mensagem repetida e exaurida pelas mídias, mas, em âmbito escolar, pode trazer inovação se for apresentada a partir de um confronto pessoal com o contexto atual, mundial e local.

Partindo dessa premissa, o presente artigo apresenta uma síntese da dissertação de mestrado desenvolvida no Programa de Pós-graduação em Geografia da Universidade Federal de Santa Maria (UFSM). Possui como o problema de pesquisa "saber em que medida os alunos da Escola Estadual de Educação Básica Dom Pedro I, localizada em 
Quevedos, Rio Grande do Sul, Brasil, conhecem e identificam os problemas ambientais existentes nesta unidade territorial?".

Seu objetivo geral é contribuir para estudos geográficos de Cartografia Escolar enfatizando problemas ambientais de Quevedos/RS. Os objetivos específicos são: (a) compreender a percepção ambiental dos alunos do Ensino Médio por meio da construção de mapas mentais, estimulando e despertando a criatividade e (b) avaliar a eficiência do Hipermapa de Quevedos/RS para a concretização da Educação Ambiental no lugar.

Assim, acredita-se que se estabeleceu um diálogo, mediado pela Cartografia Escolar, entre o cotidiano escolar e os debates no âmbito da Educação Ambiental, contribuindo com os educadores do município de Quevedos/RS e sensibilizando os alunos frente a essa temática por meio de respostas que vem sendo formuladas ao longo do processo de formação do conhecimento e pelo conjunto das pessoas que se sentem comprometidas e que, por isso, ensaiam práticas significativas em seus lugares e perante as situações do mundo atual. As respostas? "Se orientam por um novo sentido de viver e de atuar. Por uma nova percepção da realidade e por uma nova experiência do ser" (BOFF, 2002, p. 25). Essas respostas emergem em um caminho que se faz caminhando, nas vivências, no lugar.

\section{Metodologia}

Essa investigação possui como aporte teórico o método fenomenológico, proposto pelo filósofo alemão Edmund Husserl, pelo qual é realizada a descrição e análise da consciência, isto é, o estudo dos fenômenos e dos objetos que se mostram "a nós", compreendendo o sentido, tanto de ordem física quanto de caráter cultural (CHAUÍ, 2006). Consiste em uma investigação pautada na experiência e na percepção, no "darnos" conta da realidade circundante, superando a fragmentação positivista.

A partir do recorte espacial do município de Quevedos/RS (figura 1), adotouse como sujeitos da pesquisa o representado pelo corpo discente da Escola Estadual de Educação Básica Dom Pedro I, uma vez que estes consolidam as pretensões sobre os saberes escolares e as vivências do lugar. A pesquisa contou com a participação de todos os alunos matriculados no ano de 2015 nos três anos do Ensino Médio, da referida escola, ou seja, 92 alunos ( $25 \%$ do $1^{\circ}$ ano, $37 \%$ do $2^{\circ}$ ano e $38 \%$ do $3^{\circ}$ ano).

O primeiro contato com a Escola para a realização do projeto de pesquisa foi realizado em outubro de 2014. No dia 17 de abril de 2015, foi apresentado o cronograma de atividades do projeto para apreciação da gestão escolar e dos professores.

A partir disso, a inserção no espaço escolar ocorreu por meio de quatro momentos com os alunos, no âmbito do "Seminário Integrado". Em cada momento, foram realizadas atividades que conduzam ao entendimento da percepção ambiental dos alunos, a sensibilização dos mesmos por meio do Hipermapa para concretizar-se os objetivos de pesquisa. Para cada momento realizou-se a elaboração de um diário de campo, isto é, anotações de todos os fatos relevantes durante a atividade. 


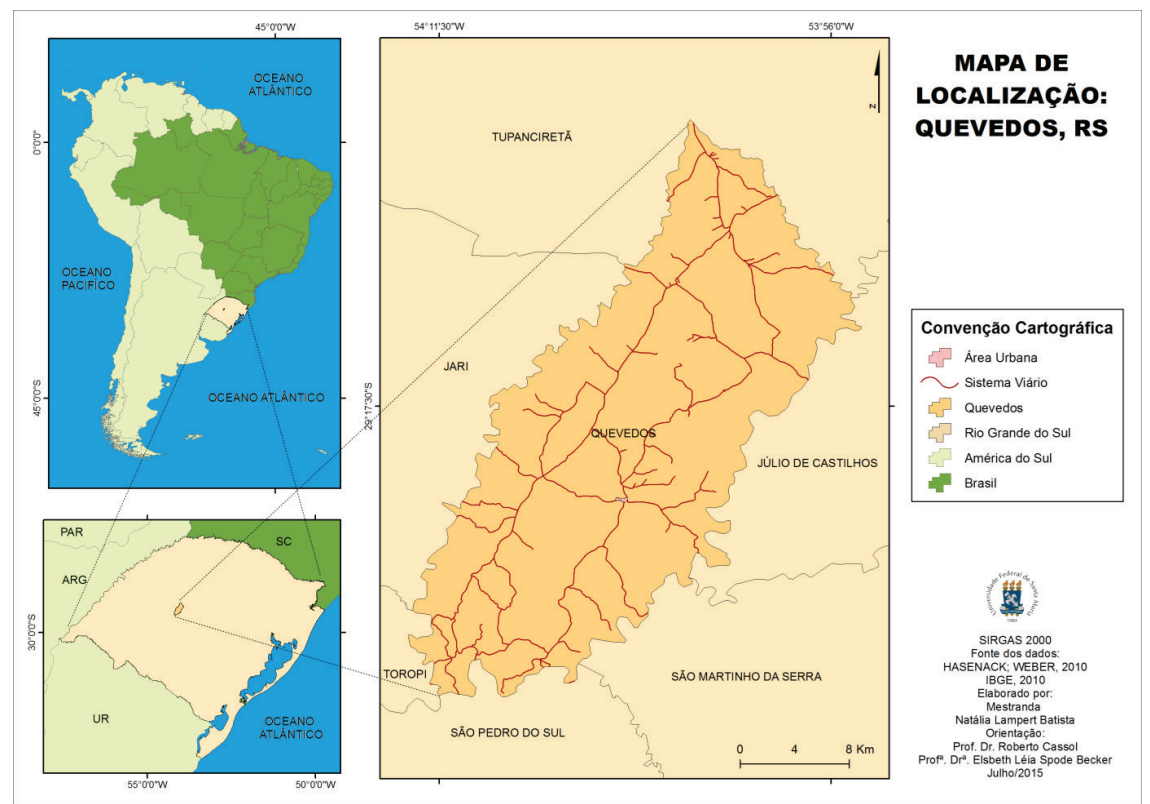

Figura 1. Mapa de localização do município de Quevedos/RS.

No primeiro encontro (13 de maio de 2015) com os alunos, fez-se a apresentação do projeto e de conceitos básicos referentes à temática a ser desenvolvida. A apresentação do projeto foi importante para que os alunos tenham consciência de todas as suas etapas. Já a abordagem dos conceitos serviu para começar a aproximá-los das concepções de Educação Ambiental defendidas. A apresentação foi realizada pela mestranda em um formato de palestra, devido ao número de alunos.

No segundo encontro (23 de junho de 2015), realizou-se a construção dos mapas mentais que são ferramentas capazes de contribuir com a verificação da percepção ambiental e vinculam-se à dimensão fenomenológica, qualitativa e descritiva, ao interpretar a representação do espaço vivido de modo subjetivo e vinculado com a concepção de mundo e com a história do educando, "[...] tendo a experiência vivida como base de todo o conhecimento e vendo as representações como objeto de investigação" (MORAES, 1997, p. 70).

Para introduzir o trabalho utilizou-se a técnica da tempestade de ideias ${ }^{1}$. Após, todos os alunos construíram mapas mentais do município durante uma manhã do Seminário Integrado da Escola. Ressalta-se que todos foram orientados a representar elementos do ambiente local. Após, foram selecionados aleatoriamente ${ }^{2} 6$ mapas mentais

1. Consiste em anotar todas as palavras que se referem ao tema a ser trabalhado para conduzir a formação de uma concepção conceitual da temática.

2. Todos os mapas mentais foram numerados no verso em ordem de entrega durante a realização da atividade. Após, sorteou-se os 6 números para cada ano (entre 1 e o número máximo de alunos). Esses números corresponderam aos mapas mentais analisados. 
por ano do Ensino Médio, resultando em 18 mapas mentais (aproximadamente 20\% do total), os quais constituíram uma amostra representativa para a descrição e a análise da percepção ambiental.

A análise dos mapas mentais foi embasada na metodologia proposta por Kozel (2007), na qual os mapas foram decodificados e analisados pelos seguintes quesitos:

a) Interpretação quanto à forma de representação dos elementos na imagem: observaram-se em um primeiro momento as formas que aparecem como: ícones, letras, mapas e linhas.

b) Interpretação quanto a distribuições dos elementos na imagem: analisaram-se como as formas estão dispostas no mapa, isto é, se estão isoladas, dispersas, horizontais, em perspectiva.

c) Interpretação quanto às especificidades dos itens: neste item a leitura aprofundou-se, subdividindo-se em: representação dos elementos naturais da paisagem, representação dos elementos da paisagem construída, representação dos elementos móveis e representação dos elementos humanos.

d) Apresentação de outros aspectos ou particulares: apresentou-se de outros elementos que permitem a decodificação da informação. Neste item, incluíram-se na metodologia baseada em Kozel (2007), as percepções sobre as questões ambientais inspiradas nas noções de ética e do saber cuidar (BOFF, 2002) e as noções de identidade e de pertencimento (TUAN, 2013).

No terceiro encontro (28 e 29 de outubro de 2015), foi realizada a atividade de sensibilização com os alunos por meio do Hipermapa construído pelos autores com base nos mapas mentais dos alunos. Cada turma foi conduzida ao laboratório de informática, onde o recurso didático já estava instalado nos computadores. Os alunos utilizaram o material, anotando palavras-chave sobre cada tela que visualizaram. Após, retornaram a sala de aula, com as palavras-chave em mãos, e redigiram um texto destacando a realidade ambiental do município.

Foram sorteados ${ }^{3} 18$ textos para análise que se pautou na interpretação quanto às especificidades dos itens (KOZEL, 2007): existência da abordagem de elementos naturais da paisagem, dos elementos da paisagem construída, dos elementos móveis e dos elementos humanos, bem como nas noções de ética e do saber cuidar (BOFF, 2002) e as noções de identidade e de pertencimento (TUAN, 2013). Porém, observou-se que as análises tornavam-se repetitivas, ou seja, as percepções apresentadas se repetiam. Por isso, optou-se em trabalhar na versão final da dissertação com 9 textos ( 3 de cada turma).

Por fim, no quarto encontro (15 de dezembro de 2015), foi realizada a apresentação dos resultados (parciais) da pesquisa, em formato palestra, a comunidade escolar, como forma de retorno e agradecimento ao espaço e ao tempo concedido.

3. Todos os textos foram numerados no verso em ordem de entrega durante a realização da atividade. Após, sorteou-se os 6 números para cada ano (entre 1 e o número máximo de alunos). Esses números corresponderam aos textos analisados. 


\section{Os mapas mentais e as percepções dos alunos do ensino médio do município de Quevedos/RS}

As metodologias de ensino no ambiente escolar, muitas vezes, permanecem engessadas sem permitir a participação efetiva do aluno, abordando um lugar que os alunos não conhecem, não pertencem. Leem-se acriticamente mapas de locais ausentes, sem questionar, sem participar do processo criativo de construção do mapa. As representações gráficas, como o mapa mental, podem estabelecer outro olhar do educando frente à realidade, permitindo que ele atue como um mapeador consciente, construindo de modo significativo seu entendimento do espaço em que está inserido.

Ao construir os mapas mentais, os alunos necessitam "dar-se conta" dos elementos do espaço vivido (ALES BELLO, 2006). Isso, não é uma tarefa fácil. Exige conhecer o lugar, o ambiente local. Os mapas mentais construídos pelos alunos são imagens e representam uma articulação entre os elementos constitutivos do espaço vivido, demonstrando como eles entendem o ambiente local. A linguagem dos mapas é a semantização que os alunos fazem de seu município enquanto espaço de vivência, de sensações e de percepções.

Assim, "el conjunto de mapas ambientales nos oferece interesantes elementos para examinar los modos de entender, conceptualizar e imaginar la naturaleza, sus transformaciones y los grados de aceptación o rechazo ante ellas"4 (HOLLMAN, 2014, p. 112). Ao mesmo tempo, as representações livres podem chamar a atenção para as raízes éticas e espirituais dos atuais problemas ambientais. Os mapas mentais nos convidam a encontrar soluções e promovem o desejo de mudança na técnica e também no pensamento fragmentado do ser humano.

Sob a luz dessa argumentação, foram apresentados os mapas mentais dos alunos dos três anos de Ensino Médio. Ressalta-se que as abordagens e as leituras (por ano de escolarização) demostram diferentes entendimentos da realidade ambiental do município. É perceptível que o tempo de estudo traz novas visões sobre a temática, sendo inclusive, mais relevante na leitura espacial do que a própria idade e tempo de moradia dos educandos. Para aprofundar essa análise, realizou-se a leitura dos mapas mentais por ano, a qual é apresentada a seguir.

\section{Análise dos mapas mentais dos alunos do $1^{\circ}$ ano}

Este item aborda a análise dos mapas mentais elaborados pelos alunos de $1^{\mathrm{o}}$ ano, os quais são apresentados na figura 2. Essa forma de expressão gráfica apresenta a percepção dos educandos sobre o lugar (Quevedos/RS).

4. [Nota de tradutor] "O conjunto de mapas ambientais nos oferece interessantes elementos para examinar os modos de entender, conceituar e imaginar a natureza, suas transformações e os graus de aceitação ou não sobre ela". 

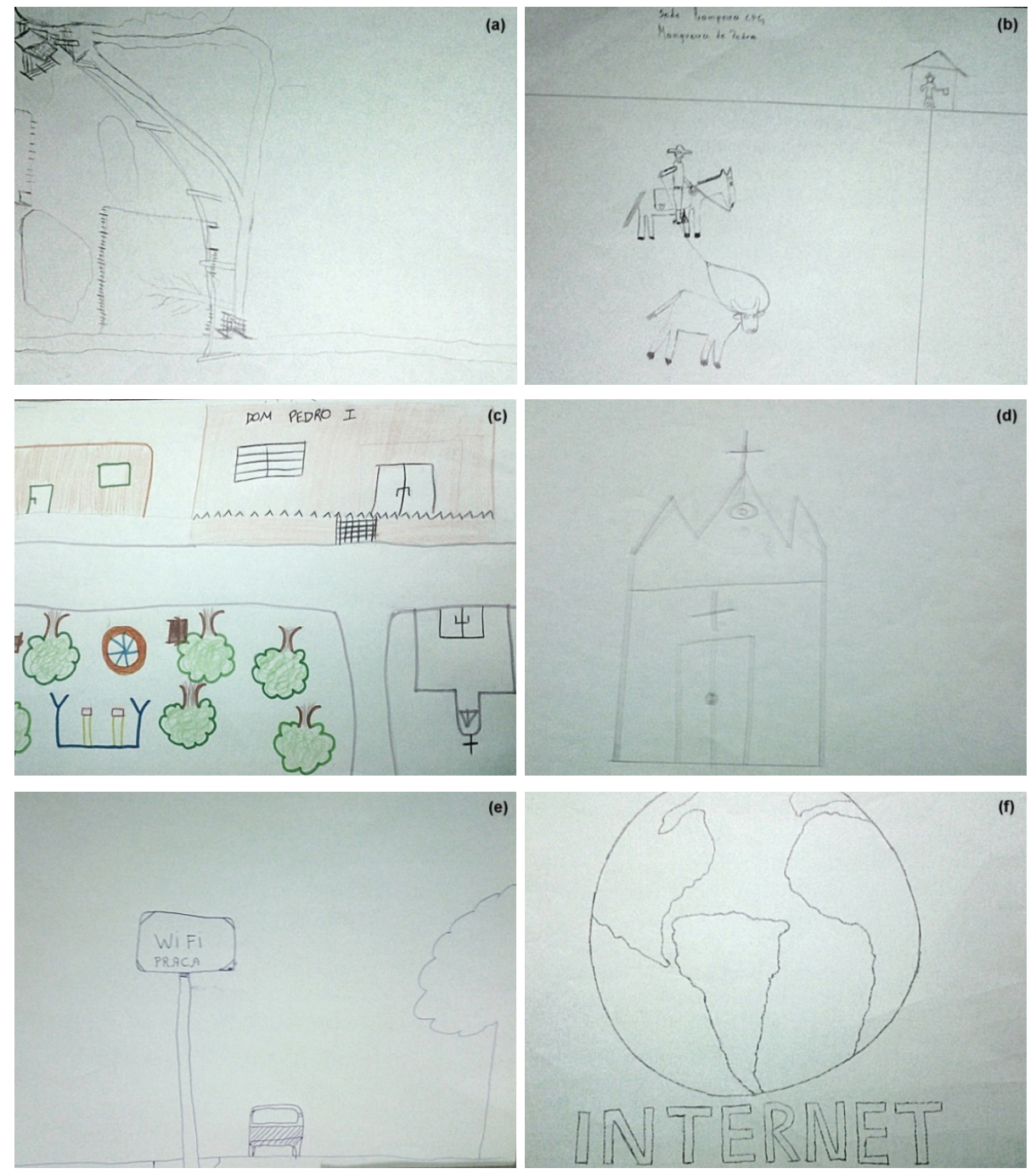

Figura 2 (a, b, c, d, e e f). Mapas Mentais de alunos de $1^{\circ}$ ano do Ensino Médio.

\section{a) Interpretação quanto à forma de representação dos elementos na imagem}

Como proposto por Kozel (2007), a primeira análise dos mapas mentais consiste em reconhecer as formas impressas nas representações. Assim, a linguagem presente nas imagens construídas pelos alunos do $1^{\circ}$ ano (figura 2 ) evidencia uma pluralidade quanto à forma de representação. As figuras 2a, 2b, 2c, 2d e 2e são marcadas pela presença predominante de ícones que demostram os elementos da realidade. Já o mapa mental da Figura $2 \mathrm{f}$ é marcado pela presença de mapas (convencionais), o que remete aos elementos 
estudados em sala de aula. Nas figuras $2 \mathrm{~b}, 2 \mathrm{c}, 2 \mathrm{~d}$ e $2 \mathrm{f}$, destacam-se também a presença de letras, isto é, de textos explicativos para facilitar a compreensão do leitor.

\section{b) Interpretação quanto à distribuição dos elementos na imagem}

Em uma segunda fase de observação ainda há uma leitura incipiente, onde se destacam as distribuições dos elementos. No caso dos mapas mentais construídos pelos alunos de $1^{\circ}$ ano, observa-se que a figura 2 a apresenta uma distribuição assimétrica, isto é, apenas um lado da folha foi utilizado o que remonta a necessitada de trabalhos na escolarização inicial que possibilitem o desenvolvimento das noções espaciais como a lateralidade.

As figuras $12 \mathrm{~b}$ e $12 \mathrm{e}$ apresentam uma representação horizontal, o que remete a um entendimento do espaço em um nível de abstração bidimensional, ou seja, não há visualização vertical dos elementos constitutivos do lugar. A figura $2 \mathrm{c}$ apresenta o mapa em perspectiva, estabelecendo assim um referencial central na folha e as noções iniciais de distância em relação às bordas da mesma. Já as figuras $2 \mathrm{~d}$ e $2 \mathrm{f}$ compreendem representações isoladas, isto é, que não demostram relação direta com os demais elementos do ambiente e, por isso, precisam ser lidas enquanto elementos com significados mais amplos e com relações mais abstratas.

\section{c) Interpretação quanto às especificidades dos itens}

Nesta etapa a leitura começa a aprofundar-se, destacando as representações dos elementos naturais e dos da paisagem construída, dos elementos móveis e dos humanos. No caso dos mapas mentais analisados, percebe-se que o seu imaginário (figura 2a, 2b, 2c, $2 \mathrm{~d}$ e 2e) remonta claramente os elementos da paisagem natural acrescida da paisagem construída, bem como a presença da representação dos elementos humanos e móveis. O primeiro mapa mental (2a) traz a noção de estações do ano, características do clima Subtropical, pois o estudante representou uma árvore sem as folhas, remetendo a vegetação decidual e a estação do inverno.

Os elementos móveis e humanos ficam claramente evidenciados na figura $2 \mathrm{~b}$. A vida no campo, o contato com os animais, destacando aspectos da lida ${ }^{5}$ campeira gaúcha, atrelada ao cavalo e a pecuária, são os elementos dispostos nesta figura formando a imagem do aluno mapeador. Além disso, a imagem aponta também a ideia dos Rodeios ou Festas Campeiras realizadas no município pelos Centros de Tradições Gaúchas (CTGs) e que estão muito presente no cotidiano dos alunos e do lugar, ou seja, uma memória coletiva fortemente marcada na memória individual e que colabora para o entendimento do ambiente local.

A figura $2 \mathrm{c}$ remete aos elementos humanos e naturais constituintes de parte da área urbana do município, ressaltando a escola, a Igreja Católica, a residência e a praça

5. Termo regional para se referir a trabalho. 
(espaço de convivência dos jovens no local). Assim, há uma síntese do espaço vivido urbano.

A figura 2d aponta apenas os elementos construídos destacando a Igreja Histórica de 1820. Isto conduz a duas leituras essenciais. A primeira refere-se à importância da religiosidade para o mapeador e a segunda a sua interpretação do patrimônio histórico como integrante do ambiente. Essa percepção ficou evidenciada, posteriormente, no trabalho com o Hipermapa quando os alunos visualizavam fotografias históricas do município de "lugares que não existem mais" e imediatamente questionavam "Onde fica isso?", "Eu não conheço esse lugar" e ao clicar na tecla "ver no mapa" mencionavam "Mas isso não poderia ter sido destruido", "As pessoas de Quevedos não cuidam da sua história" (Diários de Campo, 2015).

Já as figuras 2e e $2 \mathrm{f}$, não faz referência direta às representações dos elementos naturais nem aos elementos humanos, mas vincula-se aos elementos da paisagem construída e aos elementos móveis, ou seja, ao vínculo lugar-mundo, o que remete diretamente as características da modernidade líquida (BAUMAN, 2001). O aluno considera que o que existe de mais importante no ambiente de Quevedos é, por exemplo, a Praça, onde há internet gratuita e ele pode conectar-se com o mundo. Além disso, permite apontar que os referenciais de interesse e, por decorrência, os problemas ambientais não estão atrelados ao lugar, mas sim aos espaços ausentes, aqueles trabalhados no livro didático, as notícias na mídia e as informações disponíveis no mundo virtual.

Assim, as figuras 2a, 2b, 2c e 2d remontam a realidade do lugar de vivência e da relação mapeador-ambiente. Observa-se que embora a grande maioria dos alunos $(80 \%)$ resida no município a mais de 10 anos, demonstram que não há uma leitura ambiental local atrelada às características peculiares ao município e ao espaço de vivência, bem como o descompasso entre os recursos cartográficos utilizados em sala de aula para trabalhar as questões ambientais com a realidade local. Contudo, há uma busca por reunir elementos que remetam as características ambientais de Quevedos o que releva que os educandos apresentam-se em um estágio de síntese passiva (ALES BELLO, 2006), isto é, observam a realidade, identificam alguns elementos, mas não conseguem estabelecer ligações diretas entre o que vem e o seu significado efetivo para o contexto municipal.

\section{Análise dos mapas mentais dos alunos do $2^{\circ}$ ano}

Neste item abordar-se-á a percepção ambiental dos alunos de $2^{\circ}$ ano. A figura 3 evidencia os seus mapas mentais, destacando o seus entendimentos sobre Quevedos. 

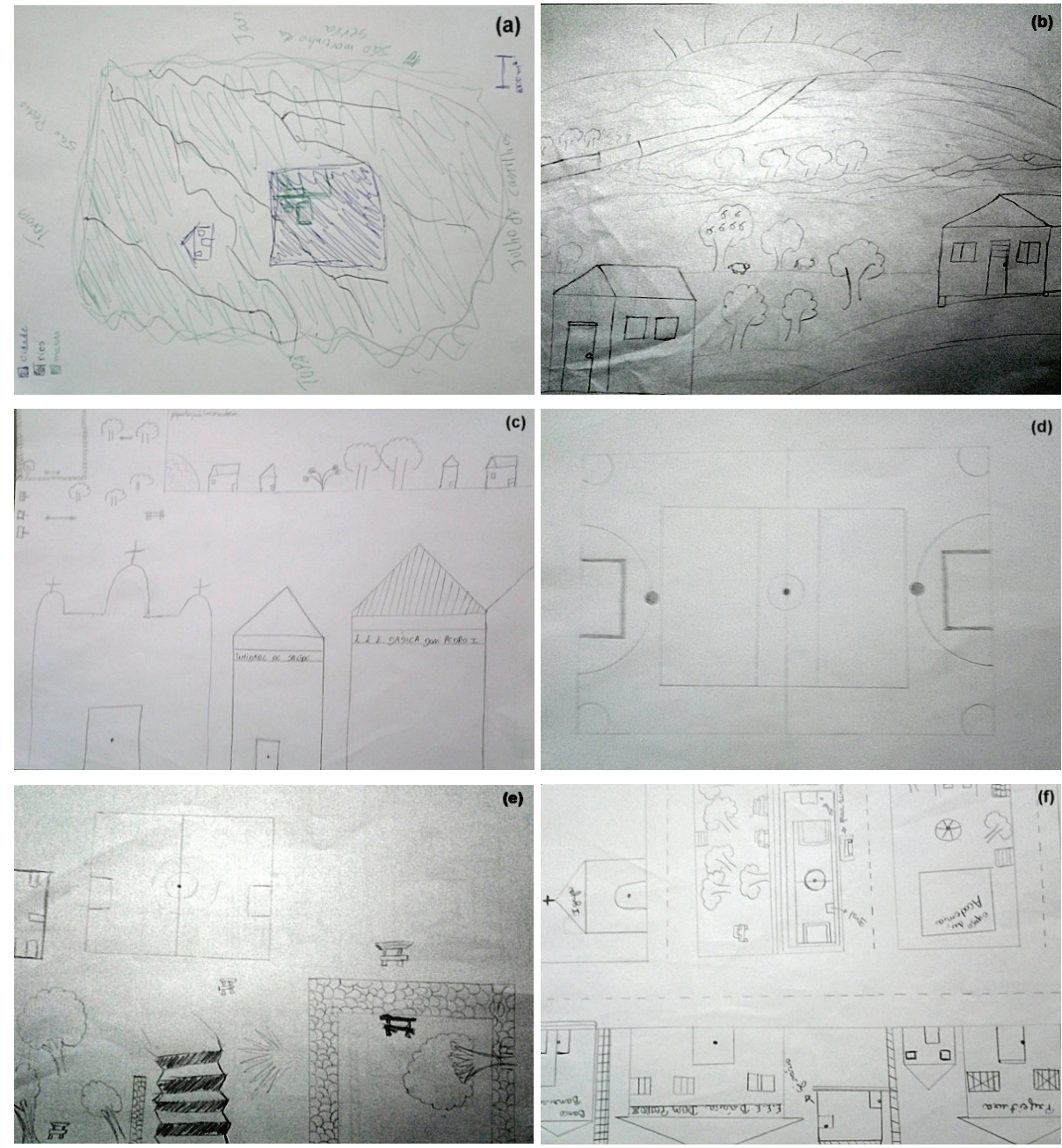

Figura 3 (a, b, c, d, e e f). Mapas Mentais de um Aluno de $2^{\circ}$ ano do Ensino Médio.

\section{a) Interpretação quanto à forma de representação dos elementos na imagem}

As representações construídas pelos alunos do $2^{\circ}$ ano (figura 3) são diversas, apontando diferentes olhares sobre o mesmo objeto de análise a realidade ambiental do município de Quevedos. A figura 3a é marcada pela representação tradicional dos elementos da paisagem como a casa, o rio e afluentes. Além disso, observa-se a presença de uma preocupação cartográfica, isto é, foi inserida a legenda e a escala (que mesmo não condizendo com a proporção entre a representação e a realidade) remete ao estudo dos mapas e seus elementos em sala de aula. Já as figuras 3b, 3c, 3d, 3e e 3f são marcadas 
pela presença predominante de ícones que representam os elementos da realidade que constituem os mapas mentais como casas e árvores.

\section{b) Interpretação quanto à distribuição dos elementos na imagem}

No caso dos mapas mentais construídos pelos alunos de $2^{\circ}$ ano, observa-se que todos apresentam as representações bem distribuídas na folha o que permite identificar que as noções de espaço estão mais elaborados, mesmo ainda apresentando lacunas no desenvolvimento de noções cartográficas bastante evidentes nos mapas em que há a ausência da visão vertical ${ }^{6}$, como a figura $3 c$, mas que não desmerecem a abordagem ambiental traçada.

Já as figuras 3a, 3e e 3f apresentam esse tipo de visão, que está associada a uma maior abstração da realidade e, consequentemente, ao estudo dos mapas e ao desenvolvimento de uma alfabetização cartográfica mais efetiva. As figuras $3 \mathrm{e}$ e $3 \mathrm{f}$ misturam visões horizontais ${ }^{7}$ e verticais, o que remete a uma transição no entendimento do espaço, ou seja, os alunos estão em um processo de aprendizagem sobre as representações espaciais.

\section{c) Interpretação quanto às especificidades dos itens}

No caso dos mapas mentais analisados, percebe-se que o imaginário dos alunos (figura 3a, 3b, 3c, 3e e 3f) articula a representação dos elementos da paisagem natural com da paisagem construída e com representação dos elementos humanos e móveis.

No o mapa da figura 3a, observa-se que o estudante busca apresentar uma visão de totalidade agregando espaço rural e urbano, ou seja, traz a noção que o município é constituído por área urbana e área rural, porém apresenta uma generalização cartográfica exagerada demonstrando que possui em seu imaginário uma leitura muito naturalista do espaço rural, destacando apenas as matas e a cidade na legenda proposta.

A figura $3 \mathrm{~b}$ mostra a visão do campo para o estudante, articulando elementos humanos e naturais em harmonia. Já as figuras $3 \mathrm{c}, 3 \mathrm{~d}$, 3e e $3 \mathrm{f}$ representam apenas o ambiente urbano, destacando elementos da paisagem antrópica e a vegetação, colocando o conceito de ambiente no sentido natureza, isto é, o ambiente como presença de elementos naturais preservados. Esse fato também foi observado no contexto da sala de aula, pois uma aluna ao receber o material para desenhar perguntou a sua colega "o que eu desenho?" e obteve como resposta "coloca as árvores, o rio e desmatamento".

Logo, as linguagens associadas aos mapas mentais elaborados pelos alunos do $2^{\circ}$ ano evidenciam a relação homem/sociedade em uma interação histórica, cultural e social e apresentam como preocupação a representação das "coisas do lugar" e o ambiente do município, porém também se percebe o desconhecimento frente à realidade ambiental do município como totalidade, permanecendo-se em uma análise pontual do espaço de vivência cotidiana.

6. Como se os elementos estivessem sendo vistos de um avião. Visão do alto, de sobrevoo.

7. Visão dos elementos do espaço como os alunos visualizam diariamente. Visão frontal do objeto. 


\section{Análise dos mapas mentais dos alunos do $3^{\circ}$ ano}

Na figura 4 são apresentados os mapas mentais dos alunos de $3^{\circ}$ ano do Ensino Médio, os quais possuem um entendimento mais global sobre o município de Quevedos/ $\mathrm{RS}$ e, consequentemente, leituras ambientais mais complexas sobre o espaço vivido.
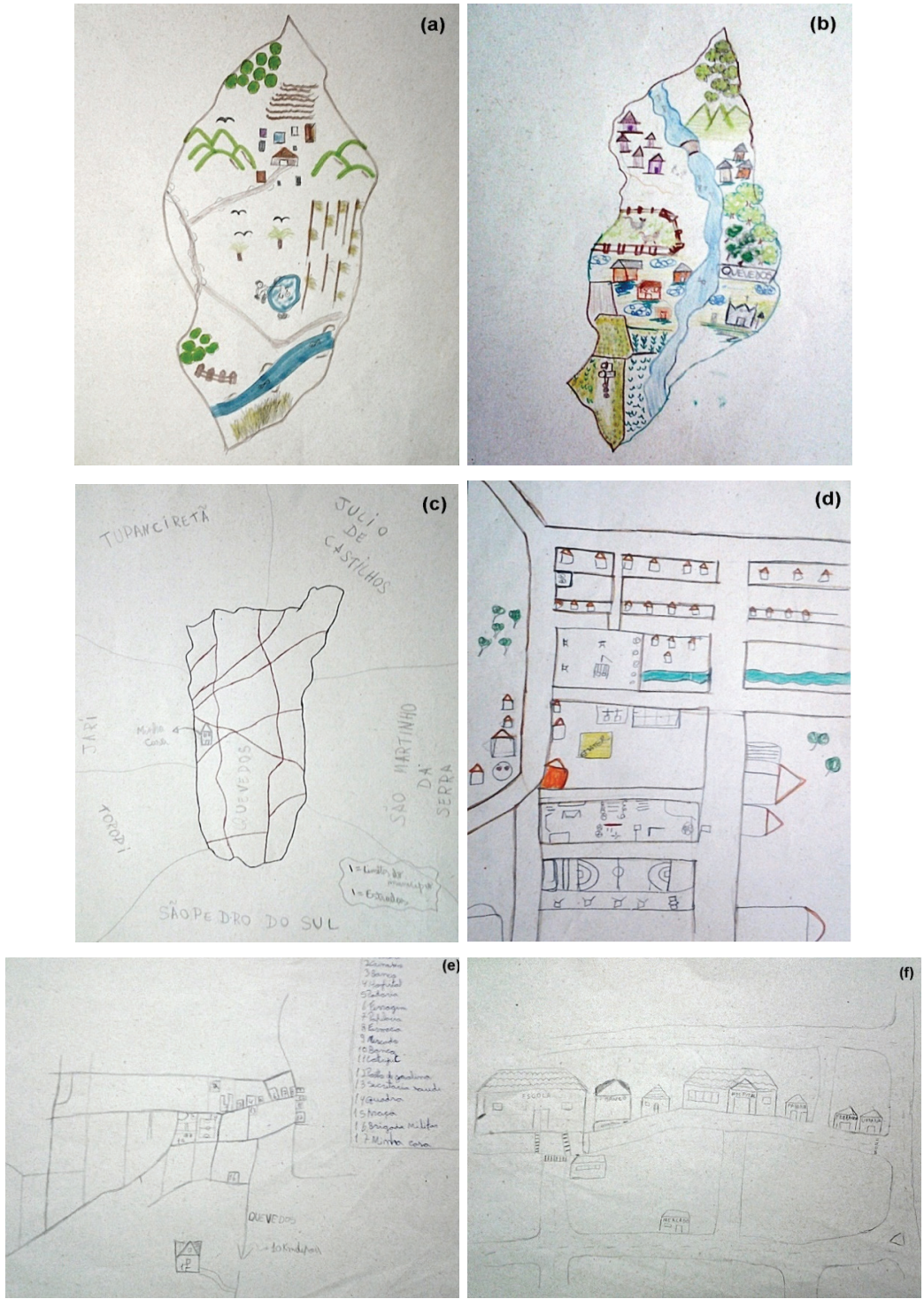

Figura 4 (a, b, c, d, e e f). Mapas Mentais de um Aluno de $3^{\circ}$ ano do Ensino Médio. 


\section{a) Interpretação quanto à forma de representação dos elementos na imagem}

As construções sígnicas das figuras $4 \mathrm{a}, 4 \mathrm{~b}, 4 \mathrm{~d}$ e $4 \mathrm{f}$ são marcadas pela presença de ícones que representam a realidade ambiental do município de Quevedos. Já as 4c e $4 \mathrm{e}$, percebe-se a utilização de elementos que remetem a forma dos mapas tradicionais ou cartesianos, não havendo identificação de elementos ambientais apenas dos limites políticos e elementos da paisagem construída (a residência).

\section{b) Interpretação quanto à distribuição dos elementos na imagem}

Todos os mapas mentais, exceto o da figura 4f, evidenciam o espaço vivido do aluno mapeador com elementos bem distribuídos na folha, mas mesclando visões horizontais, em perspectiva e verticais. Contudo, a predominância dos elementos da visão vertical demostram uma melhor alfabetização cartográfica e, consequentemente, um melhor entendimento do universo dos mapas. Assim, os alunos apresentam-se em um estágio de transição para a compreensão das representações cartográficas mais avançadas que as turmas anteriores, o que, logicamente está associado a sua maior escolaridade. A figura 4f, que ainda vincula-se a visão horizontal acaba sendo um resquício e uma evidência importante de que ainda há alunos que necessitam de um trabalho mais intenso com relação à Cartografia Escolar, pois não estão acompanhando o restante da turma.

\section{c) Interpretação quanto às especificidades dos itens}

$\mathrm{Na}$ figura $4 \mathrm{a}$ e $4 \mathrm{~b}$, percebe-se a forte influência de elementos naturais da paisagem, associados aos elementos da paisagem construída e aos elementos humanos, em menor escala. Assim, apesar de apresentar certa generalização, o aluno identifica elementos chave na realidade ambiental do município, o que permite identificar uma compreensão mais global do conceito de ambiente, isto é, aquele que considera o natural e o antrópico associado ao espaço regional. Além disso, os elementos presentes no mapa mental demostram uma maior diversidade com relação ao ambiente conhecido e vivenciado fazendo o aluno representar elementos chave na realidade ambiental.

$\mathrm{Na}$ figura 4c e na 4e não há identificação de elementos ambientais apenas dos limites políticos e da residência do aluno (elementos da paisagem construída). Isso permite inferir que o aluno mapeador encontra-se em um estágio de síntese passiva em relação ao ambiente, isto é, um caminho anterior à percepção (ALES BELLO, 2006). Porém, há inserções da linguagem cartográfica.

Com relação aos mapas das figuras $4 \mathrm{~d}$ e 4f, o grande destaque é para os elementos da paisagem construída e representação dos elementos humanos. Nota-se, então, que para esses alunos a interpretação do ambiente está fortemente atrelada as transformações geradas pelo ser humano no ambiente.

Os três mapas das figuras $4 a, 4 b$ e $4 c$, todavia, apresentam uma noção de totalidade com relação ao município de Quevedos, identificando que esse possui uma área urbana e uma área rural fato desconsiderado nos mapas das figuras 4d, 4e e 4f. Além 
disso, (os mapas 4a, 4b e 4c) apresentam o município em um formato semelhante a sua divisão política, o que remete a um conhecimento cartográfico básico sobre o local.

As figuras $4 \mathrm{a}$ e $4 \mathrm{~b}$ possuem certa riqueza de detalhes com relação às características ambientais do município como: o relevo, os diferentes cultivos e intensidades de modernização no campo, a vegetação natural, a pecuária, a área urbana e as moradias rurais, as estradas, os animais e o ser humano (pescador). Já a figura 4c, preocupa-se mais com os limites políticos e com o sistema viário. As figuras 4d, 4e e 4f apresentam a área urbana com maiores detalhes que os mapas mentais das turmas anteriores, mas não destacam a noção de município. Destacam-se, na figura 4d, os elementos naturais da área urbana como o Córrego da Aguada e a vegetação.

Apesar da generalização e da abstração nas representações, os mapas mentais dos alunos do $3^{\circ}$ ano apresentam uma percepção ambiental bem mais aguçada que dos outros anos do Ensino Médio, com maior detalhamento do município e articulando o espaço urbano e o rural. Ademais, há uma evidente preocupação com o formato do município e com a representação das múltiplas variáveis ambientais existentes. Essa percepção mais aguçada e detalhada pode estar vinculada ao maior tempo de estudo, pois os conteúdos desenvolvidos na escola, associado à maior maturidade da turma, pode auxiliar a leitura mais completa da realidade.

\section{Apresentação de outros aspectos ou particulares sobre os mapas mentais dos alunos do ensino médio}

Com base no exposto, observa-se que a linguagem presente nos mapas mentais dos alunos evidencia uma pluralidade de concepções espaciais que relacionam percepções vinculadas ao lugar e ao ambiente do município, mas também reproduzem elementos característicos do mundo globalizado.

Em relação às referências ambientais vinculadas aos espaços vividos, os alunos de $1^{\circ}$ e $2^{\circ}$ ano demonstram dificuldades para definir o que é e como se apresenta o quadro ambiental de Quevedos enquanto totalidade. Há uma leitura ambiental mais pontual do espaço de vivência. Nesse sentido, pode-se inferir que a abordagem generalizada dos temas ambientais produz certo desconhecimento do ambiental local e, consequentemente, surge à dificuldade de relacionar conceitos sobre questões ambientais com o espaço vivido.

Retoma-se, então, a ideia de que quando os problemas ambientais não são mencionados na perspectiva do lugar, o educando não constrói uma cultura ambiental ou um desejo e o compromisso de preservação com o espaço vivido.

Já os alunos do $3^{\circ}$ ano demonstram um maior entendimento do conceito de ambiente e evidenciam conhecerem o município em sua totalidade, o que possibilita uma leitura mais condizente com o espaço geográfico local e, por sua vez, remete a sentimentos identitários, de pertença e de cuidado com o lugar.

Observa-se, então, que os alunos do $1^{\circ}$ ano realizam uma leitura mais superficial do lugar, mais fragmentada e pautada no espaço vivido mais próximo (a casa, a escola, 
o ponto de lazer). Enquanto, no $2^{\circ}$ ano, percebe-se a transição entre os saberes e os conhecimentos escolares. Os alunos transitam entre o "meu espaço" e o "espaço comum". Nos $3^{\circ}$ anos conseguem, em geral, entender o município em sua totalidade, destacando elementos de todos os distritos/localidades.

Assim, como constatado por Hollman (2014, p. 111), observa-se que "a pesar de este pasaje a un grado de abstracción, en algunos casos es posible identificar un mayor grado de vinculación con imágenes ambientales en la forma de nominar las problemáticas ambientales"8 e outras a percepção ambiental permanece a nível de síntese passiva e não é apresentada claramente no mapa mental.

Todavia, nesta perspectiva, a linguagem da Cartografia Escolar, por meio dos mapas mentais, pode contribuir com o Ensino de Geografia e com a construção da noção de pertencimento dos alunos e, consequentemente, para o desenvolvimento de uma cultura ambiental do lugar, pois permite a análise e a reflexão sobre as representações e sobre o lugar gerando um vínculo de afetividade e de cuidado com o ambiente que faz parte do seu cotidiano.

\section{Educação Ambiental e Cartografia Escolar: o Hipermapa em pauta}

As mudanças do atual contexto científico, social e natural não podem ser contidas nem evitadas. Há, portanto, uma grande transição cultural para a qual necessitamos estar preparados. Capra (1982) avalia que durante a fase de reavaliação e renascimento cultural é importante minimizar as rupturas e reconhecer que a dinâmica da mudança é uma interação dialética. Nessa interação, segundo o I Ching chinês, um dos livros mais antigos de sabedoria da humanidade "[...] o antigo é descartado, e o novo é introduzido. Ambas as medidas se harmonizam com o tempo, não resultando daí, portanto, nenhum dano" (CAPRA, 1982, p. 31). A interação dialética da mudança pode ser melhor percebida, compreendida e refletida quando conhecida na totalidade.

A Educação Ambiental aparece, então, como um viés de reflexão no contexto das ciências, na Educação Básica e no uso das tecnologias, possibilitando uma leitura mais reflexiva dos aspectos levantados pela discussão ambiental.

Para ilustrar o funcionamento do recurso desenvolvido, a figura 5 apresenta a sua Tela Principal de onde parte todos os caminhos e para onde todas as Telas Temáticas Secundárias tendem a retornar, isto é, na Tela Principal há 14 atalhos, possibilitando que o aluno comece a explorar o material por 14 caminhos diferentes. Utilizou-se um mapa imagem, pois se acredita que este é o que melhor expressa à complexidade da realidade do município. Todos os layers estão presentes, mas seu entendimento profundo necessita de um vasto conhecimento sobre o município.

Cada tela secundária estará articulada com uma tecla "início" que permite retornar a tela principal e a outras Telas Secundárias ou ainda avançar até Telas Terciárias para aprofundar determinado tema.

8. [Nota do tradutor] "Apesar destas paisagens apresentarem certo grau de abstração, em alguns casos é possível identificar um maior vínculo com imagens ambientais na forma denominada: problemas ambientais". 


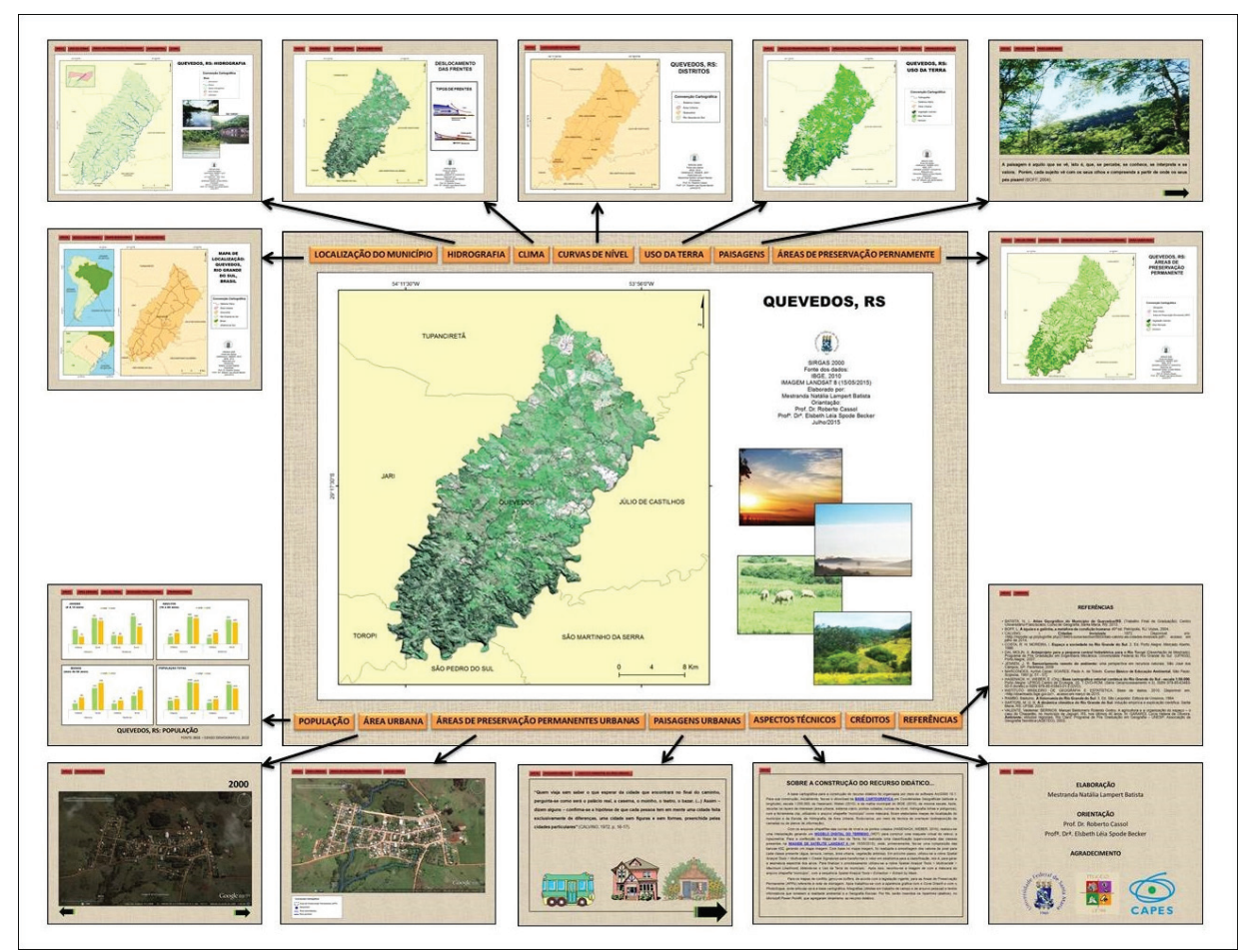

Figura 5. A tela principal do Hipermapa e suas possibilidades exploratórias.

Em sua testagem com os alunos de Ensino Médio do município de Quevedos/ RS, percebeu-se que com o Hipermapa chamou a atenção dos alunos para paisagens e elementos do espaço geográfico que, mesmo constituindo o espaço de vivência, não são observados no dia a dia, isto é, despertou-lhes uma inquietação para identificarem aqueles elementos que estão presentes no espaço, mas que não foram representados no mapa mental.

Além disso, ao trabalhar com recursos visuais interativos e com o espaço de vivência local, as noções de pertença e de identidade podem aflorar o olhar para o lugar em que estão inseridos e valorizar aquilo que geralmente não é observado com toda a atenção que merece, despertando o desejo de cuidar e evidenciando a necessidade de uma ética que impõe a responsabilidade.

Para a análise das contribuições do Hipermapa para a sensibilização ambiental, os 9 textos (sorteados para análise) foram comentados, buscando identificar se há uma nova percepção dos alunos em relação ao ambiente e as questões ambientais. Essa análise foi pautada na interpretação quanto às especificidades dos itens (KOZEL, 2007): existência da abordagem de elementos naturais da paisagem, dos elementos da paisagem construída, dos elementos móveis e dos elementos humanos, bem como nas noções 
de ética e do saber cuidar (BOFF, 2002) e as noções de identidade e de pertencimento (TUAN, 2013).

Quadro 1. Textos elaborados pelos alunos de $1^{\circ}$ ano do Ensino Médio.

\section{TEXTO 1}

Quevedos é uma cidade muito bonita apesar de ser pequena, mas está evoluindo cada dia mais. Evoluindo com mais casas, pessoas e também mais movimento de pessoas de fora.

Quevedos também é um município muito produtivo nas áreas rurais com plantio de soja, milho, trigo e fumo. Na área da saúde o atendimento é bom.

Também tem muitos meios para as pessoas se refrescarem no verão como o Rio Toropi, Lajeados, sangas, etc.

Apesar de todas essas belezas também tem desmatamento para abrir lavouras, bastante poluição de áreas pegando água para passar produtos tóxicos e na cidade sangas com muito esgoto.

\section{TEXTO 2}

Quevedos é um lugar simples, mas de alguns anos para cá vem crescendo e se desenvolvendo em algumas áreas.

Tem umas áreas preservadas, mas tem outras áreas que estão sendo prejudicadas pelo uso de agrotóxicos.

Gostei muito do que vi no Hipermapa, pois tem foto do pôr-do-sol e de lindas paisagens que achei que nem existiam aqui. Aprendi também que existem áreas de preservação permanente que eu não sabia que tinha que ter aqui.

\section{TEXTO 3}

Quevedos é um lugar calmo e com bastante natureza, com agricultura farta e bastante pessoas trabalhando nas áreas rurais.

Em nosso município não há tanta poluição, porém há bastante desmatamento. Mas isso já se tornou normal então não preocupa a população, pois acham que os problemas que isso causa nunca atingirão o nosso município.

Devemos cuidar do nosso município, pois não queremos que os recursos naturais acabem.

Fonte: Atividade na Escola $-1^{\circ}$ ano Out $/ 2015$.

Os três textos são marcados pela presença de elementos naturais da paisagem (paisagens naturais, pôr-do-sol), de elementos da paisagem construída (plantações, desmatamento, poluição, agricultura e desmatamento) e de elementos humanos (pessoas), apresentando uma leitura espacial mais abrangente que a apresentada nos mapas mentais, ou seja, trabalhando com o município em nível de totalidade e ultrapassando a leitura do espaço vivido imediato (a casa, a escola e o espaço de lazer). 
Além disso, os textos demostram um sentimento enraizamento, porém é nítida a percepção de que os alunos tendem a pensar que "ser uma cidade pequena" é algo negativo, fato também identificado nos mapas mentais quando o aluno mapeador desenhou o símbolo da internet e o Wi-Fi da Praça como elementos significantes. O aluno gosta de seu município, mas gostaria que ele fosse "grandioso" como prega a sociedade do espetáculo que nasce na modernidade líquida (BAUMAN, 2001). Esse sentimento topofóbico em relação às "cidades pequenas" também remonta a ideia de estar no lugar, mas querer o mundo, o espaço, como destaca Tuan (2013) ao abordar as categorias de análise da ciência geográfica espaço e lugar

[...] O lugar é a segurança e o espaço é a liberdade: estamos ligados ao primeiro e desejamos o outro. O que é lar? É a velha casa, o velho bairro, a velha cidade ou a pátria. [...] Tempo e lugar são componentes básicos do mundo vivo, nós os admiramos como certos. Quando, no entanto, pensamos sobre eles, podem assumir significados inesperados e levantam questões que não ocorreria indagar (TUAN, 2013, p.11).

A novidade está na abordagem de cuidado que surge nos textos como: "Devemos cuidar do nosso município, pois não queremos que os recursos naturais acabem”. Nos mapas mentais, os alunos apenas apresentavam seu espaço vivido imediato e a leitura conduzia a um entendimento de "espaço em paz", lugar onde não ocorrem conflitos ambientais. Tudo é ponderado em harmonia. Agora, surgem inquietações sobre o agrotóxico, os desmatamentos, a poluição, sobre as áreas de preservação permanente, sobre o descuido. Abre-se um novo olhar sobre Quevedos e, consequentemente, vê-se a sensibilização com a temática abordada.

Quadro 2. Textos elaborados pelos alunos de $2^{\circ}$ ano do Ensino Médio.

\section{TEXTO 4}

\section{Uma pequena cidade}

Vivemos em uma pacata cidade no centro do Rio Grande do Sul que possui muitas belezas naturais, tradição apurada, uma produção monocultora de soja (a principal de nosso municipio), entre outras.

Viver em Quevedos apesar de ser uma cidade pequena é muito especial, é um lugar calmo, com pouca violência.

A população se concentra mais nas áreas rurais de nosso município, tendo uma pequena parte residindo na área urbana... Temos rios que passam pela nossa cidade e interior.

Enfim, posso dizer que o nosso municipio é maravilhoso, pois gosto muito de morar aqui, devido às belezas que nossa cidade nos oferece. Gostaria de dizer que tenho muito orgulho de ser uma quevedense. 


\section{TEXTO 5}

O municipio de Quevedos é pequenos, mas em compensação tem suas paisagens lindíssimas, pessoas boas, ou seja, generosas um com o outro. Ele de pouco a pouco está evoluindo, na população, na produção de grãos, no gado, nos alimentos.

Apesar de ser uma cidade pacata tem tudo o que precisamos como educação, saúde, prefeitura, lugares de lazer, de divertimentos, lugares públicos alguns com pouca ampliação, mas que ajuda muito a população.

Todos com suas tradições, seus costumes, alguns bem bagual outros mais simples e assim vai todos respeitando cada opinião. Um lugar bom de viver, sendo no campo o na cidade os dois são lugares incriveis.

Enfim, como falar de Quevedos, tenho orgulho de morar aqui, foi aqui que nasci e sei tudo o que sei hoje graças a Quevedos. Vai sempre estar guardado em minhas lembranças!

\section{TEXTO 6}

A realidade ambiental do município de Quevedos está muito boa, mas pode melhorar. Há pessoas que se importam mais com o dinheiro deixando de lado os limites necessários como: tem pessoas que abrem lavouras, desmatam, colocam agrotóxicos perto de nascentes e de rios matando peixes também estragando as paisagens naturais e matando os animais ao seu redor. Eu acho que tinham que criar algo para punir de parar o desmatamento e com tudo que pode fazer mau para nós e para a nossa natureza.

Quevedos é um bom lugar para viver, mas precisa ser bem cuidado, se não tudo pode acabar!

Fonte: Atividade na Escola $-2^{\circ}$ ano. Out $/ 2015$.

O quarto e o quinto textos destacam presença de elementos naturais da paisagem (belezas naturais), de elementos da paisagem construída (produção, monocultura de soja, gado e alimentos) e de elementos humanos (o indivíduo). Demostra um forte sentimento topofílico como observado nos fragmentos: "Enfim, posso dizer que o nosso município é maravilhoso, pois gosto muito de morar aqui, devido às belezas que nossa cidade nos oferece. Gostaria de dizer que tenho muito orgulho de ser uma quevedense" e "Enfim, como falar de Quevedos, tenho orgulho de morar aqui, foi aqui que nasci e sei tudo o que sei hoje graças a Quevedos. Vai sempre estar guardado em minhas lembranças!". Contudo, a abordagem ainda permanece restrita "ao que há de bom", assim como nos mapas mentais.

Já no sexto texto em que predominam elementos da paisagem construída (lavouras, desmatamento, agrotóxicos, degradação de rios e perda da biodiversidade), elementos humanos (o indivíduo) e elementos móveis (dinheiro), o entendimento do município ultrapassa a memória visual e articula-se profundamente com o saber cuidar, com o desejo de mudança e de proteção ao ambiente local como observado em "Quevedos é um bom lugar para viver, mas precisa ser bem cuidado, se não tudo pode acabar!'”. Pode-se, até mesmo, afirmar que a leitura de espaço do estudante associa-se, 
mesmo que de forma incipiente, ao desejo de uma nova ética pautada no respeito ao ambiente e a vida.

Quadro 3. Textos elaborados pelos alunos de $3^{\circ}$ ano do Ensino Médio.

\section{TEXTO 7}

O município de Quevedos sofre muito com o desmatamento para novas lavouras, muitas matas ciliares somem, a poluição nos rios é grande tanto de lixo como de veneno, muitos lavam as máquinas usadas nos rios. A água consumida por nós não e das melhores e às vezes a água é marrom e nos temos que usar a água assim. O desmatamento continua crescendo e os órgãos competentes não tomam nenhuma atitude.

Há alguns anos havia algumas árvores de araucária ao lado da Igrejinha, essas árvores foram derrubadas dando lugar a uma casa, sendo que esse tipo de mata está em extinção e não pode ser derrubada. Ninguém tomou uma atitude e resolveu esse problema, nem a prefeitura, ao redor da Igrejinha como o Casarão (que eu não conheci) deveriam ser patrimônio e não podiam sofrer alterações nem dentro nem do lado de fora

\section{TEXTO 8}

\section{Carta aberta às gerações}

Habitantes do municipio de Quevedos! Penso que vocês devem notar as mudanças ocorridas durante a vida de ambos nesta cidadezinha, o quanto tudo foi alterado na paisagem, na construção das casas. É muito importante pararmos para pensar nas consequências disto, essas mudanças teriam trazido só beneficios a nós?

As lavouras, as plantações em geral tonaram conta dos campos e a vegetação que a 15 anos era frequente a nossos olhos, isso e claro uma forma de renda desses "fazendeiros", porém alterou muito de nosso município. Vejo as casas e as construções como uma coisa boa, sinal que nossa população está crescendo e assim trazendo novas gerações para viver aqui.

Neste breve relato, posso notar que essas mudanças em nosso território iriam apenas acontecer, não esperava apenas que fossem tão rápidas. Espero que vocês que estão vindo de novas gerações cuidem dos nossos campos, dos nossos rios, das nossas florestas, para que aqui continue sendo um pedacinho do céu.

\section{TEXTO 9}

O municipio de Quevedos vem perdendo sua identidade ambiental devido ao crescimento humano e socioeconômico dos últimos anos. A paisagem quevedense vem mudando constantemente, principalmente, na sede nos últimos anos.

A urbanização da cidade, juntamente com o cultivo da monocultura da soja, vem extinguindo ambientes que deveriam ser preservados. Por mais que existam paisagens naturais com fauna e flora diversificada, não há licenciamento de nenhum órgão público para preservação e conhecimento destas. O meu medo é que essas constantes mudanças privem as futuras gerações das experiências ecológicas que hoje os jovens quevedenses podem vivenciar.

Quanto aos recursos hídricos, podemos apontar um descaso para com as áreas aquíferas da região. Mesmo que não seja um apontamento que derive de muita preocupação, já que não há perigo imediato da contaminação desses, podemos levar o exemplo da Aguada da 
igrejinha como a situação de maior descaso quanto aos bens fluviais do município. Um ponto que costumava ser para pesca e recreação hoje está diminuindo e é alvo da deposição de dejetos e encontra-se em completa contaminação por material fecal, impedindo por completo o seu uso público.

Matas ciliares escassas, descaso e falta de cuidado pintam o quadro ambiental do municipio de Quevedos, em particular a área urbana.

Fonte: Atividade na Escola $-3^{\circ}$ ano. Out $/ 2015$.

Os textos elaborados pelos alunos de $3^{\circ}$ ano apresentam-se mais abrangentes que os das demais turmas, assim como os mapas mentais, perpassando pela observação dos elementos naturais da paisagem e sua degradação (o desmatamento para novas lavouras, das muitas matas ciliares, a contaminação dos rios por venenos, campos, rios e florestas), pelos elementos da paisagem construída (Igrejinha, plantações) e de elementos móveis (máquinas, transformações) e elementos humanos (população quevedense).

O sétimo texto é marcado pela indignação com o descaso com o cuidado e com a qualidade ambiental, bem como com a percepção da necessidade de preservar o patrimônio construído do município que está em acelerado processo de destruição. O autor traz a ideia de esse lugar que precisa urgentemente ser (re)pensado, trazendo novas posturas e novas condutas para não perder sua identidade. Isso remete as discussões propostas por Leff (2001), Morin (2003), Novo (2009) e Naredo (2010). Isto é, reflete a necessidade de buscar novas formas de ver o mundo e de interagir com ele.

A sensação de incerteza presente no relato do texto 8 também pode ser associada ao Evangelho da Perdição, discutido por Morin (2003) no livro Pátria Terra. Neste capítulo, o autor defende a certeza da incerteza. A busca constante por salvar a alma e o mundo por meio de tecnologias e de crenças diversas, que acabam não dando conta dessa missão. Remete a um saudosismo de um mundo que não existe mais ou pode deixar existir pela incerteza gerada pela pós-modernidade ou modernidade líquida. Esse é justamente o sentimento que envolve o aluno escritor. Assim, há um evidente apelo pelo cuidado, pela preservação do que ainda existe no lugar. Há uma busca por uma certeza de que o que o faz gostar e se sentir pertencente ao município continue a existir.

Por fim, no nono texto fica evidente o desejo de novas posturas para reduzir a perda de sua identidade, bem como as noções de identidade e de pertencimento a esse lugar. $\mathrm{O}$ autor traz em sua consciência todo o caminho percorrido pela doutrina do dinheiro e da tecnologia (GIDDENS, 1991; NOVO, 2009) para explorar o lugar e obter, cada vez mais lucro. Em contraponto, apresenta a noção de que a qualidade de vida depende de planejamento e de impor limites ao "progresso" desmedido (imposto pelos preceitos positivistas aplicados ao capitalismo). Aponta a "crise do nosso tempo" proposta por Leff (2001), isto é, a fragmentação de pensamento que conduz a perda das noções de identidade, de pertença e de saber cuidar.

Os textos identificam uma percepção em construção, mas que caminha no sentido oposto a degradação ambiental. Novos ideais estão presentes no pensamento dos 
alunos de Quevedos/RS. Alguns em estágios mais incipientes e outros com uma postura forte e crítica com relação à realidade.

Essa análise possibilita identificar que os alunos de $1^{\circ}$ ano trazem imbricados em seu pensamento a preocupação com a conservação ambiental e o desejo de desenvolvimento em um sentido de crescimento econômico, fato que está associado ao pensamento fragmentado cartesiano da sociedade atual, mas também ao desenvolvimento desses alunos enquanto pensadores. Parte-se de uma sociedade extremamente positivista, cartesiana, e começa-se a olhar para o mundo de forma diferenciada, complexa. Esse novo olhar necessita ser estimulado e também de um período de transição para passar a vigorar entre os estudantes em formação.

O mesmo ocorre nos textos dos alunos de $2^{\circ}$ ano. Aqui, pode-se destacar o sentimento de pertença, a noção da necessidade de saber cuidar e de conservar o ambiente. A novidade é que eles não estão tão enraizados o desejo de "progresso" e de "crescimento econômico" o que demostra um olhar um pouco mais crítico sobre o espaço de vivência.

Os alunos de $3^{\circ}$ ano são os que mais apresentam construído um sentimento de pertença em relação ao município de Quevedos/RS, bem como um entendimento de que há problemas ambientais no lugar e que os moradores é que precisam se dar conta e resolvê-los. Os textos são marcados pela indignação com o descuidado com o lugar. Ambiente esse entendido em uma dimensão mais ampla, que envolve o natural e o social ou construído. Além disso, envolvem um pensamento que destaca que a realidade ambiental do município de Quevedos/RS, precisa urgentemente ser (re)pensada, trazendo formas de agir e de se relacionar com o espaço vivido.

Assim, observa-se que ao trabalho com o Hipermapa estimulou a refletir sobre como está o ambiente municipal. Certamente, as percepções ambientais do município não são oriundas do recurso didático, mas ele auxiliou a sensibilização frente às questões ambientais e ao direcionamento do pensamento para a temática em estudo. Ao solicitar que os alunos desenhassem o espaço vivido muitas informações relevantes foram expressas, mas não ocorreu um claro direcionamento para o debate da crise ambiental e sim para os espaços de vivência com um olhar de predominante harmonia.

Ao se utilizar o Hipermapa, os alunos focaram sua atenção nos elementos que necessitam ser repensados no lugar, bem como ampliaram a visão de "espaço vivido próximo" para a totalidade do município. Dessa maneira, se essas discussões continuarem em pauta na escola, pode conduzir a novas atitudes e a novas formas de ver o mundo, reforçando ideias que já estão presentes no pensamento dos estudantes, mas que necessitam ser estimuladas.

Este debate é o primeiro passo de um longo caminho. Caminhada essa cheia de obstáculos, que necessita renúncias e convicção para ser continuada. Como menciona Maria Novo (2007), é preciso resistir à tentação do "Deus dinheiro" para assim libertarse das amarras da modernidade e vislumbrar um mundo mais saudável, mais humano e mais feliz. 


\section{Considerações finais}

As leituras espaciais dos alunos mostraram-se diversas, alterando-se com o passar dos anos de estudo. Ou seja, os alunos do $1^{\circ}$ ano realizam uma leitura pautada no espaço vivido mais próximo (a casa, a escola, o ponto de lazer) com dificuldades de interrelacionar os aspectos da realidade do município como um todo. Já no $2^{\circ}$ anocomeça a ocorrer uma passagem de entendimento do "meu espaço" para o "espaço comum". Por fim, nos $3^{\circ}$ anos conseguem, em geral, entender o município em sua totalidade, destacando elementos de todos os distritos/localidades.

Verificou-se que a construção de mapas mentais, em sala de aula, pode ser utilizada nos momentos iniciais do trabalho sobre um determinado tema ou conteúdo, quando o objetivo é trazer os conhecimentos e as representações prévias dos alunos. Assim, utilizou-os para compreender a percepção ambiental (inicial) dos alunos do Ensino Médio, como mapeadores conscientes, estimulando e despertando a criatividade.

De forma similar aos mapas mentais, os textos elaborados pelos alunos são um procedimento importante nos momentos finais de uma unidade de estudo, já que oportuniza a retomada e a verificação dos conhecimentos construídos, pois se caracteriza pela semantização pessoal dos conceitos construídos ao longo da vida e da atividade desenvolvida, desencadeando e oportunizando condições de expressão do mundo vivido.

A pesquisa permitiu contribuir para estudos geográficos de Cartografia Escolar com ênfase nos problemas ambientais de Quevedos/RS e responder ao problema de pesquisa evidenciado, apontando que os alunos apresentam-se em um processo de síntese passiva, conhecendo superficialmente o município.

Portanto, conclui-se que a representação que emerge dos mapas mentais deve ser considerada como "um modo de ver" e quando trabalhada e associada às transformações históricas, sociais, econômicas, políticas, técnicas e artísticas, permitem aprofundar conhecimentos escolares, associados a outros recursos de ensino, como o Hipermapa, e motivar mudanças e transformações importantes e emergentes no pensamento das futuras gerações.

\section{Referências}

ALES BELLO, A. Introdução à fenomenologia. Bauru, SP: Edusc, 2006.

BAUMAN, Z. Modernidade líquida. Rio de Janeiro: Jorge Zahar, 2001.

BERTIN, M. O ensino da geografia na Tríplice Fronteira (Puerto Iguazú/AR, Foz do Iguaçu/BR e Ciudad del Este/PY), e o turismo como possibilidade de reflexão das representações sociais e espaciais. (Tese de doutorado). Universidade Federal do Rio Grande do Sul, Instituto de Geociências, Programa de Pós-graduação em Geografia, Porto Alegre, RS: 2014.

BOFF, L. Saber cuidar: ética do humano - compaixão da terra. 8. ed. Petrópolis, RJ: Vozes, 2002. 
BUZAI, G. D; DURÁN. D. SIG: ensenãr e investigar com sistemas de información geográficas. Buenos Aires: Traquel, 1997.

CALLAI, H. C. O município: uma abordagem geográfica nos primeiros anos da formação básica. In: CAVALCANTI, L. de S. Temas da Geografia na escola básica. Campinas, SP: Papirus, 2013.

CAPRA, F. O ponto de mutação. São Paulo: Cultrix. 1982.

CHAUÍ, M. Convite a Filosofia. São Paulo: Ática. 2006.

FLICK, U. Introdução à pesquisa qualitativa. Tradução Joice Elias Costa. 3. ed. Porto Alegre: Artmed, 2009.

GIDDENS, A. As consequências da modernidade. São Paulo: Ed. da UNESP, 1991.

HOLLMAN, V. Mapas, imaginarios y memoria ambiental en Argentina. In: Revista Geografares, Edição Especial, p.96-117, Janeiro-Agosto, 2014.

KENSKI, V. M. Tecnologias e ensino presencial e a distância. 9. ed. Campinas, SP: Papirus, 2003.

KOZEL, S. Mapas mentais - uma forma de linguagem: perspectivas metodológicas. In: KOZEL, S; SILVA, J. C; GIL FILHO, S. F. Da percepção a Cognição a representação: reconstruções teóricas da Geografia Cultural e Humanística. São Paulo: Terceira Margem, 2007.

LEFF, E. Epistemologia Ambiental. São Paulo: Cortez, 2001.

MORAES, A. C. R. Meio ambiente e ciências humanas. 2. ed. São Paulo: HUCITEC, 1997.

MORIN, E. Terra-pátria. Porto Alegre: Sulina, 2003.

NAREDO, J. M. Raíces económicas del deterioro ecológico y social. 2. ed. Madrid: España editores, 2010.

NOVO, M. El Desarrollo Sostenible. Su dimensión ambiental y educativa. Madrid: MCGraw Hill, 2007.

SILVA, M. R. O ensino-aprendizagem das categorias geográficas nas séries iniciais do ensino fundamental no município de Riacho das Almas-PE. (Dissertação de Mestrado). João Pessoa: Programa de Pós Graduação em Geografia, Universidade Federal da Paraíba, 2010.

TUAN, Y. Espaço e Lugar: a perspectiva da experiência. Londrina: Eduel, 2013. 


\section{NATÁLIA LAMPERT BATISTA}

Graduada em Geografia pelo Centro Universitário Franciscano, Mestra e Doutoranda no Programa de Pós-Graduação em Geografia da Universidade Federal de Santa Maria.

Endereço postal: Departamento de Geografia e Geociências, Centro de Ciências Naturais e Exatas, Universidade Federal de Santa Maria. Caixa Postal 97105-900, Santa Maria, RS, Brasil.

E-mail: natilbatista3@gmail.com

\section{Roberto CASSOL}

Professor Doutor em Geografia Humana pela USP. Atualmente, professor no Departamento de Geografia e Geociências e no Programa de Pós-graduação em Geografia da Universidade Federal de Santa Maria.

Endereço postal: Departamento de Geografia e Geociências, Centro de Ciências Naturais e Exatas, Universidade Federal de Santa Maria. Caixa Postal 97105-900, Santa Maria, RS, Brasil.

E-mail: rtocassol@gmail.com

\section{Elsbeth LéIa Spode Becker}

Professora Doutora em Agronomia pela UFSM. Atua como professora no Centro de Ciências Humanas do Centro Universitário Franciscano e no Instituto São José.

Endereço postal: Centro Universitário Franciscano, Conjunto I. Rua dos Andradas, . Santa Maria, RS. CEP: 97010-032.

E-mail: elsbeth.geo@gmail.com

Recebido para publicação em janeiro de 2016 Aprovado para publicação em julho de 2016 